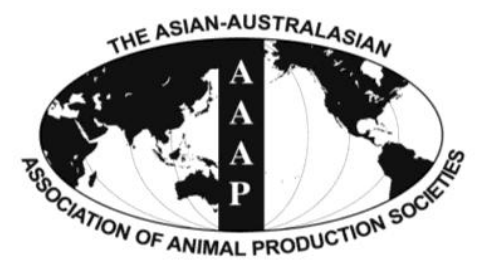

Asian Australas. J. Anim. Sci.

Vol. 26, No. 11 : 1562-1568 November 2013

http://dx.doi.org/10.5713/ajas.2013.13132

www.ajas.info

pISSN 1011-2367 elSSN 1976-5517

\title{
Effect of Indigenous Herbs on Growth, Blood Metabolites and Carcass Characteristics in the Late Fattening Period of Hanwoo Steers
}

\author{
D. H. Kim ${ }^{1}$, K. H. Kim, I. S. Nam ${ }^{2}$, S. S. Lee' ${ }^{3}$ C. W. Choi ${ }^{4}$, W. Y. Kim ${ }^{5}$, E. G. Kwon, \\ K. Y. Lee, M. J. Lee ${ }^{6}$, and Y. K. Oh* \\ National Institute of Animal Science, RDA, Suwon, 441-706, Korea
}

\begin{abstract}
This study was conducted to evaluate the effects of indigenous herbal supplements on growth, blood metabolites and carcass characteristics in the late fattening period of Hanwoo steers. In a 6 month feeding trial, thirty Hanwoo steers $(647 \pm 32 \mathrm{~kg})$ were allotted to one of 5 treatment groups, control (basal diet contained lasalocid), licorice, clove, turmeric and silymarin, with six steers per pen. All groups received ad libitum concentrate and $1 \mathrm{~kg}$ rice straw/animal/d throughout the feeding trial. Blood samples were collected at the beginning, middle, and the end of the experiment and the steers were slaughtered at the end. Blood glucose, triglyceride, total protein, and albumin concentrations were higher in the turmeric treatment compared with other treatments. Blood urea nitrogen and creatinine concentrations were highest $(\mathrm{p}<0.003$ and $\mathrm{p}=0.071$, respectively) in steers treated with silymarin. Alanine aminotransferase activity was lower $(\mathrm{p}<0.06)$ for licorice and silymarin compared with the control group. There were no alterations in serum aspartate aminotransferase and gamma glutamyltransferase activities as a consequence of herb treatments $(\mathrm{p}=0.203$ and 0.135 , respectively). Final body weight, body weight gain, average dairy gain and dry matter intake were not significantly different among treatments. Yield grade, marbling score and quality grade were higher for silymarin group than those of the control group $(\mathrm{p}<0.05)$. Therefore, the results suggest that silymarin can be used an effective dietary supplement as an alternative to antibiotic feed additive and a productivity enhancer, providing safe and more consumer acceptable alternative to synthetic compounds during the late fattening period of steers. (Key Words: Herb, Carcass Characteristic, Blood Metabolite, Hanwoo Steer)
\end{abstract}

\section{INTRODUCTION}

The main reason for the wide use of antibiotic feed additives was their beneficial effects on health status, performance and nutrient utilization as well as prevention of acidosis, coccidiosis, bloat and liver abscess (Matsuoka et al., 1996; Nagaraja and Chengappa, 1998). However, the trend toward more natural animal production systems has led to an increasingly critical attitude on the part of

\footnotetext{
* Corresponding Author: Young Kyoon Oh. Tel: +82-31-2901665, Fax: +82-31-290-1660, E-mail: oh665@korea.kr

${ }^{1}$ Department of Animal and Food Sciences, University of Kentucky, USA.

2 Department of Animal Life and Environmental Science, Hankyoung National University, Korea.

3 Division of Applied Life Science, Gyeongsang National University, Korea.

${ }^{4}$ Department of Animal Resources, Daegu University, Korea.

${ }^{5}$ Korea National College of Agriculture and Fisheries, Korea.

${ }^{6}$ Semi Feed Tech. Co. Ltd., Seoul, Korea.

Submitted Mar. 3, 2013; Accepted May 29, 2013; Revised Jun. 27, 2013
}

consumers about antibiotics in feed. Moreover, since 2005 South Korea has been gradually reducing the 44 types of antibiotics which were allowed to be mixed with feed. Consequently, the addition of antibiotics in all livestock feed has been totally banned since June 2011 .

Herbal preparations have been used for various purposes because of their antioxidant and antimicrobial properties (Nakajima et al., 1996; Davidson and Naidu, 2000; Yun et al., 2003). The use of herbal preparations is a natural alternative to antibiotic use in animal nutrition. Plant secondary metabolites have been shown to modulate ruminal fermentation and to improve nutrient utilization in ruminants (Hristov et al., 1999). Herbs have been commonly used in aromatherapy for humans and may have similar effects in animals providing a decrease in stress and an improvement in their welfare. Nevertheless, few studies have been conducted on the effect of medicinal herbs in Hanwoo steers. Therefore, we have selected four medicinal herbs which are known to have antimicrobial properties and have been widely used to treat liver diseases in South Korea, i.e. licorice, clove, turmeric, and silymarin (Pompei et al., 
1979; Nakajima et al., 1996; Dorman and Deans, 2000; Chon and Kim, 2005). It was hypothesized that the supplementation of medicinal herbs with antimicrobial properties may alter rumen microbial activity and rumen fermentation of beef cattle fed a high-concentrate diet. Consequently, the herbs may influence cattle production efficiency. Therefore, the objective of this study was to determine whether these herbs can be used as a dietary supplement in the late fattening period of Hanwoo steers to improve production efficiency. Hence, we evaluated the response of Hanwoo steer to these herbs by measuring feed intake, growth rate, feed efficiency, carcass characteristics and blood metabolites.

\section{MATERIALS AND METHODS}

\section{Animals, diets and management}

A feeding trial was conducted for 6 months at the National Agricultural Cooperative Federation Farm located in Anseong, South Korea. Thirty Hanwoo steers (647 \pm 32 $\mathrm{kg}$ ) were used in a completely randomized design to determine the effects of herbals as a dietary supplement in the late fattening period. The steers were allotted to one of 5 treatment groups with six steers per pen. Treatments were as follows: control (basal diet contained lasalocid), licorice, clove, turmeric and silymarin (Semi Feed Tech. Co. Ltd., Seoul, South Korea). The experiment was carried out from 25 to 32 months of age. All groups received ad libitum concentrate and $1 \mathrm{~kg} / \mathrm{animal} / \mathrm{d}$ rice straw throughout the feeding trial until slaughter. Ingredient composition and chemical analysis of the concentrate diets are shown in Table 1. The DM content of the rice straw was $88.4 \%$, and the CP, NDF, and ADF contents were 4.4, 49.2, and $31.9 \%$ (DM basis), respectively.

Steers were fed the experimental diets twice daily at 0800 and $1700 \mathrm{~h}$, and had free access to mineral blocks. Each treatment was fed to steers via an individual gate feeding system. Water was freely accessible through the automatic waterers. At the end of the feeding trial, all animals were slaughtered at a commercial abattoir (National Agricultural Cooperative Federation, Seoul, South Korea).

\section{Sampling, measurements and chemical analysis}

Throughout the feeding trial, daily feed intake was

Table 1. Ingredient composition and chemical analysis of the experimental diets ${ }^{\mathrm{a}}$

\begin{tabular}{|c|c|c|c|c|c|}
\hline$\overline{\text { Items }}$ & Control & Licorice & Clove & Turmeric & Silymarin \\
\hline \multicolumn{6}{|l|}{ Ingredients (As-fed basis, \%) } \\
\hline Corn flakes & 49.9 & 49.6 & 49.6 & 49.6 & 49.6 \\
\hline Corn gluten feed & 15.3 & 15.3 & 15.3 & 15.3 & 15.3 \\
\hline Beet pulp & 24.4 & 24.4 & 24.4 & 24.4 & 24.4 \\
\hline Molasses & 4.08 & 4.08 & 4.08 & 4.08 & 4.08 \\
\hline Vitamin-mineral additive $^{\mathrm{b}}$ & 0.33 & 0.33 & 0.33 & 0.33 & 0.33 \\
\hline Limestone & 0.55 & 0.55 & 0.55 & 0.55 & 0.55 \\
\hline Salt & 0.51 & 0.51 & 0.51 & 0.51 & 0.51 \\
\hline Yeast culture & 2.11 & 2.11 & 2.11 & 2.11 & 2.11 \\
\hline Calcium phosphate & 0.36 & 0.36 & 0.36 & 0.36 & 0.36 \\
\hline Sodium bicarbonate & 0.51 & 0.51 & 0.51 & 0.51 & 0.51 \\
\hline Ammonium chloride & 0.26 & 0.26 & 0.26 & 0.26 & 0.26 \\
\hline Glycerol & 1.51 & 1.51 & 1.51 & 1.51 & 1.51 \\
\hline Lasalocid & 0.11 & - & - & - & - \\
\hline Licorice & - & 0.50 & - & - & - \\
\hline Clove & - & - & 0.50 & - & - \\
\hline Turmeric & - & - & - & 0.50 & - \\
\hline Silymarin & - & - & - & - & 0.50 \\
\hline Total & 100 & 100 & 100 & 100 & 100 \\
\hline \multicolumn{6}{|l|}{ Chemical analysis } \\
\hline Dry matter $(\%)$ & 85.6 & 86.5 & 85.6 & 86.6 & 85.5 \\
\hline Crude protein (\% of DM) & 14.3 & 14.3 & 14.0 & 14.1 & 14.3 \\
\hline Neutral detergent fiber (\% of DM) & 24.7 & 25.0 & 24.9 & 25.9 & 25.8 \\
\hline Acid detergent fiber (\% of DM) & 6.32 & 6.73 & 6.13 & 7.00 & 7.12 \\
\hline
\end{tabular}

${ }^{a}$ Steers had free access to mineral blocks (Rincal block, Daehan New Pham, Seoul, Korea; provided following nutrients per kg: I, $150 \mathrm{mg}$; Mn, $200 \mathrm{mg}$;

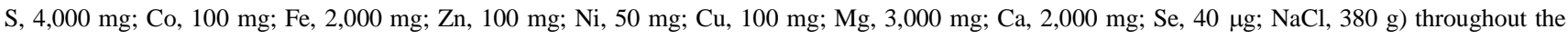
experiment.

${ }^{\mathrm{b}}$ Provided following nutrients per kg of additive (Grobic-DC, Bayer HealthCare, Leverkusen, Germany): Vit. A, 2,650,000 IU; Vit. $\mathrm{D}_{3}, 530,000$ IU; Vit. E, 1,050 IU; Niacin, 10,000 mg; Mn, 4,400 mg; Zn, 4,400 mg; Fe, 13,200 mg; Cu, 2,200 mg; I, 440 mg; Co, 440 mg. 
calculated as the difference between the daily feed supply and refusals, and weight gain was calculated as the difference between initial and final body weights.

Experimental diets were dried in a forced-air oven (at $60^{\circ} \mathrm{C}, 48 \mathrm{~h}$ ), ground through a $2-\mathrm{mm}$ screen in a Wiley mill (Model 4; Thomas scientific, Swedesboro, NJ, USA) and analyzed for moisture, $\mathrm{CP}, \mathrm{EE}$, and ash according to the procedures of AOAC (1990). The concentration of NDF corrected for residual ash was determined with heat-stable amylase and sodium sulphate according to the method of Van Soest et al. (1991), while the concentration of ADF corrected for residual ash was determined according to the procedure of AOAC (1990).

Blood samples were taken by venipuncture from the jugular vein at the beginning, middle, and the end of the experiment periods prior to the morning feeding. Blood was collected into 10-mL vacuum tubes (BD Vacutainer, Becton and Dickinson, NJ, USA) without any anticoagulant. The samples were allowed to clot for $24 \mathrm{~h}$ at $4^{\circ} \mathrm{C}$ and centrifuged $\left(2,000 \times \mathrm{g}\right.$ for $20 \mathrm{~min}$ at $\left.4^{\circ} \mathrm{C}\right)$, and serum was stored at $-70^{\circ} \mathrm{C}$ until further analysis.

Blood samples were analyzed by an automatic blood analyzer (Express Plus, Ciba-Corning, CA, USA). These included total protein, glucose, blood urea nitrogen (BUN), albumin, creatinine, total cholesterol, triglycerides, nonesterified fatty acid (NEFA), lactate, total bilirubin, aspartate aminotransferase (AST), alanine aminotransferase (ALT) and gamma glutamyltransferase (GGT).

At the end of feeding trial all steers were slaughtered after a $24 \mathrm{~h}$ fasting period. They were stunned, exsanguinated, and immediately eviscerated. Carcasses were chilled at between 0 to $2^{\circ} \mathrm{C}$ for $24 \mathrm{~h}$. The carcasses were then graded for quality and yield factors from the longissmus muscle taken at 13th rib. Quality and yield grading were performed by trained personnel of the Animal Products Grading Service in Seoul, South Korea. Carcass weight, dressing percentage, back-fat thickness and size of loin-eye area were assessed. Yield grade was classified with a scale of $\mathrm{A}, \mathrm{B}$, or $\mathrm{C}$, where $\mathrm{A}$ is high yield and $\mathrm{C}$ is low yield. Quality grade was scored on a scale of $1^{++}, 1^{+}, 1,2$, and 3 , which was mainly determined by marbling score but also by meat color, fat color and maturity. Marbling score was evaluated and scored on a scale of 1 to 9 , where 9 is very abundant and 1 is trace amounts. Fat color was scored on a scale of 1 to 7 , where 1 is creamy white and 7 is yellowish. Panel meat color was scored on a scale of 1 to 7 , where 1 is bright red and 7 is dark red. Texture was scored on a scale of 1 to 3 , where 1 is soft and 3 is firm. Maturity was scored on a scale of 1 to 9 , where 1 is young and 9 is old.

\section{Statistical analysis}

Blood data for steers within each treatment were averaged within each sampling day, and analyzed using the MIXED procedures of SAS (SAS Inst. Inc., Cary, NC, USA) with animal as random effects, and treatment, sampling day, and treatment $\times$ sampling day as fixed effects. Growth performance and carcass characteristics were subjected to statistical analysis using the GLM procedure of SAS (SAS Inst. Inc.) with animal as random effects, and treatment as fixed effects. Duncan's multiple range test was used to interpret any significant differences among the mean values of the treatments. Means are presented as least squared means.

\section{RESULTS AND DISCUSSION}

Blood profiling is considered to be one of the significant sources for judging the nutrient status and body condition, and a comparison of blood metabolites may be useful for the diagnosis of metabolic disorders. Also, it may a good indicator of the effects of herb feeding on normal physiology. Blood glucose, triglyceride, total protein and albumin concentrations were highest for the turmeric group (Table 2, p<0.001). The higher albumin concentration for turmeric may be due to the improvements of ruminal microbial protein synthesis or by greater absorption of protein. Various substances such as amino acids adhere particularly to albumin in the blood, which plays a role in their transport (Rivera et al., 2005). This is also supported by the total protein concentration being the highest in the turmeric group. Total protein in blood reflects availability of protein and albumin normally constitutes about $60 \%$ of the plasma protein in the blood of ruminants (Lohakare et al., 2006). On the other hand, the lowest albumin concentration occurred in the licorice group which indicates increases in protein synthesis in muscle as this decreases the blood albumin concentrations. This is supported by the report of Galbraith et al. (1978) who demonstrated that blood albumin concentration was decreased with increasing protein accumulation to muscle.

The increase of glucose concentration for turmeric and silymarin groups may be due to the increase of ruminal propionate which is the precursor of glucose synthesis. Over $80 \%$ of propionate absorbed into the portal blood is utilized for glucose synthesis (Steinhour and Bauman, 1988). It was reported that ruminal propionate concentration and proportion decreased in steers receiving cloves (Hosoda et al., 2006). In contrast there was no effect of peppermint and lemongrass compared with a control diet. Therefore, it appears that a specific component of the herbs, a plant secondary metabolite, likely alters the ruminal fermentation and microbial activity in ruminants. For example, aroma compounds from herbs, the essential oils, affects the rumen microbial activity and consequently alters ruminal fermentation; eugenol and thymol decrease total VFA, the 
Table 2. Effect of herbs on blood metabolites and enzymes in the late fattening period of Hanwoo steers

\begin{tabular}{|c|c|c|c|c|c|c|c|c|c|}
\hline \multirow{2}{*}{ Item $^{1}$} & \multicolumn{5}{|c|}{ Treatments } & \multirow{2}{*}{ SEM } & \multicolumn{3}{|c|}{ Statistical significance $^{2}$} \\
\hline & Control & Licorice & Clove & Turmeric & Silymarin & & $\mathrm{T}$ & $\mathrm{D}$ & $\mathrm{T} \times \mathrm{D}$ \\
\hline Glucose (mg/dL) & 73.8 & 68.9 & 64.8 & 93.3 & 81.0 & 2.92 & 0.001 & $<0.001$ & 0.015 \\
\hline BUN (mg/dL) & 12.4 & 13.5 & 14.5 & 14.7 & 16.1 & 0.50 & 0.003 & $<0.001$ & NS \\
\hline Triglyceride $(\mathrm{mg} / \mathrm{dL})$ & 33.1 & 25.1 & 27.4 & 35.1 & 26.1 & 1.67 & 0.002 & $<0.001$ & 0.092 \\
\hline Total protein $(\mathrm{g} / \mathrm{dL})$ & 6.40 & 6.25 & 6.21 & 6.67 & 6.43 & 0.05 & $<0.001$ & $<0.001$ & 0.015 \\
\hline Albumin (g/dL) & 4.39 & 4.26 & 4.41 & 4.66 & 4.46 & 0.05 & 0.003 & $<0.001$ & 0.068 \\
\hline Creatinine (mg/dL) & 1.36 & 1.39 & 1.37 & 1.33 & 1.50 & 0.03 & 0.071 & 0.003 & NS \\
\hline Total cholesterol (mg/dL) & 193 & 174 & 194 & 209 & 189 & 8.37 & NS & 0.003 & NS \\
\hline NEFA (mmol/L) & 0.25 & 0.46 & 0.49 & 0.39 & 0.44 & 0.12 & NS & 0.039 & NS \\
\hline Lactate $(\mathrm{mg} / \mathrm{dL})$ & 31.0 & 24.5 & 29.8 & 43.4 & 34.5 & 2.15 & $<0.001$ & NS & NS \\
\hline Total bilirubin (mg/dL) & 0.38 & 0.38 & 0.44 & 0.36 & 0.39 & 0.03 & NS & $<0.001$ & NS \\
\hline ALT (U/L) & 16.9 & 14.9 & 18.3 & 18.5 & 15.4 & 0.84 & 0.060 & NS & NS \\
\hline AST (U/L) & 76.5 & 77.2 & 76.9 & 81.8 & 81.6 & 2.54 & NS & NS & NS \\
\hline GGT (U/L) & 40.9 & 44.5 & 50.7 & 40.4 & 43.3 & 4.18 & NS & NS & NS \\
\hline
\end{tabular}

${ }^{1}$ BUN $=$ Blood urea nitrogen; NEFA = Non-esterified fatty acid; ALT = Alanine aminotransferase; AST = Aspartate aminotransferase; GGT = Gamma glutamyltransferase.

${ }^{2} \mathrm{~T}=$ Treatment; $\mathrm{D}=$ Sampling day.

acetate to propionate ratio and lactate concentration, and increase ruminal $\mathrm{pH}$ (Kim et al., 2009).

Blood lactate concentration was lower for the licorice group than for steers fed control diet (Table 2, $\mathrm{p}<0.001$ ). This may be due in part to more efficient utilization of lactate by ruminal bacteria in the presence of licorice. Lactic acid levels were found to increase in the rumen as well as blood in ruminants during acidosis (Harmon et al., 1985). However, it is doubtful that the licorice group were suffering acidosis because blood lactate can be a source of blood glucose via the lactic acid cycle as well as being sourced by the breakdown of muscle glycogen. However, ruminal $\mathrm{pH}$ and metabolites were not measured in the present study. Therefore, further study is required to determine the reason for the lower lactate levels in the licorice group.

Blood urea nitrogen and creatinine concentrations were highest for the silymarin group $(p<0.003$ and $p=0.071$, respectively). Urea is synthesized in the liver from ammonia absorbed from the rumen or gut, and so BUN concentration is positively correlated with the ruminal concentration of ammonia (Davidson et al., 2003). It was reported that BUN concentration was increased by peppermint and lemongrass feeding in Holstein steers (Hosoda et al., 2006), whereas ruminal ammonia nitrogen concentration was decreased with capsicum and cinnamon treatments. The change of BUN concentration was probably caused by the differences of ruminal ammonia between the herb groups and control group. In addition, BUN indicates the relative rate of carcass protein accumulation (Gettys et al., 1988). Creatinine concentration is considered to be a measure of muscle mass because a positive correlation has been found between plasma creatinine concentration and carcass weight, dressing percentage and the proportion of lean meat in the carcass (Istasse et al., 1990). The higher levels of serum creatinine and BUN in the present study reflect the increased muscle mass in steers treated with silymarin, which is supported by the results of loin-eye area, dressing percentage and yield grade (Table 4). Therefore, it suggests that silymarin supplement to a high-concentrate diet in the late fattening period produces changes in blood metabolism that may enhance production.

Alanine aminotransferase was lowest $(\mathrm{p}<0.06)$ for the licorice group whereas the turmeric and clove groups had the highest $(\mathrm{p}<0.06)$ ALT concentrations among treatments. It has been reported that these herbs have pharmacological activity. Silymarin has been used to treat numerous diseases, especially liver diseases (Gazák et al., 2007). Most of the clinical findings can be summarized by the term increased liver regeneration. Silymarin can stimulate protein synthesis and tissue regeneration in the liver (Gazák et al., 2007). Therefore, silymarin may protect the liver against drug and toxin related liver damage. The silymarin and licorice groups in the present study had lower serum ALT concentrations compared with the control group $(\mathrm{p}=0.06)$. Licorice is known to have antioxidant (Nakajima et al., 1996), anti-inflammatory (Fenwick et al., 1990) and antiviral properties (Pompei et al., 1979). Clove has been demonstrated to have antioxidant (Yun et al., 2003), antimicrobial (Dorman and Deans, 2000) and insecticidal properties (Kim et al., 2003). Turmeric has been demonstrated to have antioxidant, antimicrobial, and antiinflammatory properties (Chattopadhyay et al., 2004) as well. On the other hand, it is reported that the ingestion of herbs possibly could decrease the function of organs (Hosoda et al., 2006). Therefore, the result suggests that 
clove and turmeric supplementation to a high-concentrate diet may decrease the liver function in the late fattening period of Hanwoo steers. In contrast, the licorice and silymarin treatments had the opposite effect. However, the biochemical mechanism involved in these herbs-induced biological effects remains unclear.

There were no changes in serum AST and GGT activities as a consequence of herb treatments (Table 2, p = 0.203 and $\mathrm{p}=0.135$, respectively). Also, the time of sampling had no effect on AST and GGT activities ( $\mathrm{p}=$ 0.881 and $p=0.222$, respectively). Reduced AST levels indicate a beneficial effect on liver function (Mayer et al., 2005). Serum GGT levels are not a sensitive indicator of liver function but can be used in some situations to evaluate liver related organs. It can also be used in large animals as a screening test for generalized hepatic disease (Dehghan et al., 2011). Increases in serum ALP activity are most commonly associated with cholestasis in most species, but in hepatocyte injuries ALP activity is also increased (Kaneko et al., 2008). Even though these herbs have been used in traditional medicine in Asia to treat numerous diseases, especially hepatic disorders, the results in the present study are ambiguous whether the herb feeding to steers would have impacted the liver function because serum AST and GGT concentrations as well as total bilirubin concentration did not differ among treatments. In contrast, it suggests that these herbs fed to Hanwoo steers in the late fattening period may not have an adverse effect on liver function compared with steers fed a control diet that contained lasalocid.

Beef production in South Korea is a feedlot system where Hanwoo steers are fed an increasing high concentrate diet for more than 30 months to produce muscle with a high marbling. Thereby, the fattening period is usually coupled with high-concentrate diets in the Hanwoo industry. Feeding a high-concentrate diet is energetically more efficient for increases in beef quality and yield, however, it has adverse effects which are decreased and (or) fluctuations in feed intake in the finishing phase of Hanwoo steers (Shin et al., 2002). The erratic feed intake may result from decreased ruminal $\mathrm{pH}$ to below 6.0 or erratic $\mathrm{pH}$ which can cause a rumen disturbance and an acidic condition, and can increase the risk of ruminal acidosis with accumulation of ruminal acids and elevated osmolality of ruminal contents and blood (Nocek, 1997). Therefore, prolonged high-concentrate feeding in the late fattening period may increase the possibility of inducing metabolic disorders such as ruminal acidosis and liver abscesses. Consequently, a lengthy fattening period with a highconcentrate diet may have an adverse effect on animal health, performance and feed efficiency. Liver and gastrointestinal are the first tissues that lose mass after metabolic disorders (Ramsey et al., 2000). Moreover, liver function has a major economic impact in the beef industry because a disorder can cause decreased animal performance and carcass yield in ruminants. Although these adverse effects could be offset by antibiotic feed additives, they are no longer a possible alternative for livestock in South Korea. Few other alternatives have been demonstrated effective for Hanwoo steers.

Initial and final BW were not different among the groups (Table 3). Although the DM intake in the herb groups was numerically lower than control, there were no significant differences $(\mathrm{p}=0.356)$. Body weight gain and average daily gain were not different among treatment groups ( $\mathrm{p}=0.370$ and $\mathrm{p}=0.289$, respectively). It was reported that alfalfa extract and cinnamaldehyde had adverse effects on feed intake (Cardozo et al., 2006) and the feeding of peppermint to lactating dairy cow decreased nutrient digestibility and methane production (Hosoda et al., 2006). The ingestion of herbs possibly decreases the function of organs as well. They suggested that herb ingestion may result in subacute symptoms such as reduced feed intake and impaired nutrient utilization which negatively affect animal productivity. On the other hand, in the present study, $0.5 \%$ herb treatments added to the diet in the late fattening period had no adverse effects on growth performance when compared with steers fed a control diet that contained lasalocid.

Carcass weight and dressing percentage were not

Table 3. Effects of herbs on growth performance and feed intake in the late fattening period of Hanwoo steers

\begin{tabular}{|c|c|c|c|c|c|c|}
\hline \multirow{2}{*}{ Items $^{1}$} & \multicolumn{5}{|c|}{ Treatments } & \multirow{2}{*}{ SEM } \\
\hline & Control & Licorice & Clove & Turmeric & Silymarin & \\
\hline Initial age (month) & 25.9 & 25.7 & 25.8 & 25.6 & 25.7 & 0.32 \\
\hline Final age (month) & 32.5 & 32.3 & 32.4 & 32.3 & 32.3 & 0.34 \\
\hline Initial BW (kg) & 649 & 646 & 648 & 646 & 647 & 11.78 \\
\hline Final BW (kg) & 805 & 784 & 802 & 782 & 790 & 24.05 \\
\hline BW gain (kg) & 156 & 138 & 154 & 136 & 143 & 7.75 \\
\hline $\operatorname{ADG}(\mathrm{kg} / \mathrm{d})$ & 0.86 & 0.72 & 0.80 & 0.70 & 0.74 & 0.12 \\
\hline \multicolumn{7}{|l|}{ DMI (kg/d) } \\
\hline Concentrate & 8.06 & 7.81 & 8.00 & 7.80 & 7.86 & 0.21 \\
\hline Rice straw & 0.69 & 0.69 & 0.69 & 0.69 & 0.69 & 0.00 \\
\hline
\end{tabular}

${ }^{1} \mathrm{ADG}=$ Average daily gain; DMI $=$ Dry matter intake. 
Table 4. Effect of herbs on carcass characteristics in the late fattening period of Hanwoo steers

\begin{tabular}{|c|c|c|c|c|c|c|}
\hline \multirow{2}{*}{ Item $^{1}$} & \multicolumn{5}{|c|}{ Treatments } & \multirow{2}{*}{ SEM } \\
\hline & Control & Licorice & Clove & Turmeric & Silymarin & \\
\hline Carcass weight (kg) & 477 & 465 & 485 & 468 & 474 & 5.11 \\
\hline Loin-eye area $\left(\mathrm{cm}^{2}\right)$ & 89.3 & 85.6 & 93.7 & 88.3 & 93.0 & 1.70 \\
\hline Backfat thickness (mm) & 16.3 & 15.6 & 18.7 & 18.7 & 15.5 & 1.08 \\
\hline Dressing $(\%)$ & 61.4 & 61.5 & 60.3 & 60.0 & 62.4 & 0.76 \\
\hline Yield grade & $1.40^{\mathrm{ab}}$ & $1.60^{\mathrm{ab}}$ & $1.17^{\mathrm{b}}$ & $1.33^{\mathrm{ab}}$ & $2.00^{\mathrm{a}}$ & 0.11 \\
\hline Marbling score & $4.25^{\mathrm{ab}}$ & $3.40^{\mathrm{b}}$ & $4.17^{\mathrm{ab}}$ & $4.17^{\mathrm{ab}}$ & $5.17^{\mathrm{a}}$ & 0.12 \\
\hline Meat color & 5.00 & 5.00 & 5.00 & 5.17 & 5.00 & 0.06 \\
\hline Fat color & 3.00 & 3.00 & 3.00 & 3.00 & 3.00 & 0.00 \\
\hline Texture & $1.75^{\mathrm{ab}}$ & $2.00^{\mathrm{a}}$ & $1.67^{\mathrm{ab}}$ & $1.67^{\mathrm{ab}}$ & $1.33^{\mathrm{b}}$ & 0.10 \\
\hline Maturity & 2.25 & 2.20 & 2.50 & 2.67 & 2.67 & 0.10 \\
\hline Quality grade & $2.80^{\mathrm{ab}}$ & $2.60^{\mathrm{b}}$ & $2.83^{\mathrm{ab}}$ & $3.00^{\mathrm{ab}}$ & $3.50^{\mathrm{a}}$ & 0.14 \\
\hline
\end{tabular}

${ }^{1}$ Carcass characteristics were measured from longissmus muscle taken at 13 th rib; carcass yield grade $(3=$ high yield, $1=$ low yield $)$, grading ranges are 1 to 9 for marbling score with higher numbers for better quality $(1=$ traces, $9=$ very abundant $)$, meat color $(1=$ bright red, $7=$ dark red $)$, fat color $(1=$ creamy white, $7=$ yellowish $)$, texture $(1=$ soft, $3=$ firm $)$, maturity $(1=$ youthful, $9=$ mature $)$, quality grade $(5=$ very high quality, $1=$ low quality $)$.

${ }^{\mathrm{a}, \mathrm{b}, \mathrm{c}}$ Means in a same row with different superscripts are significantly different $(\mathrm{p}<0.05)$.

different among treatment groups (Table 4, $\mathrm{p}=0.229$ and 0.631 , respectively). Yield grade was higher for the silymarin group compared with the control group $(\mathrm{p}<0.05)$. Body weight, BW gain and average daily gain were numerically higher for the control group than the herb groups, but carcass weight was not different among the groups, although carcass weight for the clove group was 10 $\mathrm{kg}$ higher than control group. These results may possibly be due to the sedative and anxiolytic properties of herbs (Cropley et al., 2002). However, further study may be required on the effects of herbs on transport stress of Hanwoo. Marbling score was higher for silymarin, and lower for licorice than that of the control group $(\mathrm{p}<0.05)$. Texture was higher for licorice and lower for silymarin than that of control group $(\mathrm{p}<0.05)$. Marbling contributes significantly to beef's eating quality as it affects primarily flavor and juiciness, but also to texture (Temisan, 1989). Quality grade was higher for silymarin and lower for the licorice group than that of the control group $(\mathrm{p}<0.05)$, while there were no differences among the control, clove and turmeric treatments. Results indicate that marbling score and quality grade were not adversely affected by these herbs, excluding the licorice treatment.

Herbs and their preparations have been commonly used in aromatherapy and numerous diseases for humans. In addition, most studies have been focused on hepatoprotective effects in animal sciences. For instance, it was demonstrated that beneficial effects of silymarin has been proven in periparturient dairy cows (Tedesco et al., 2004) and silymarin was investigated for its effect on compromised liver where a negative energy balance primes a series of metabolic disorders in sheep (Dehghan et al., 2011). Although herbs have enormous potential to be developed as a possible alternative to antibiotics, indigenous herbs have not been considered as a dietary supplement intended for Hanwoo steers.

In conclusion, this study attempted to evaluate the potential use of indigenous herbs in the late fattening period of Hanwoo steers. The results in the present study demonstrated that silymarin treatment can improve carcass characteristics and enhance liver function without any adverse effects on growth performance and blood metabolites when compared with steers fed a control diet containing lasalocid. Therefore, silymarin may be an effective dietary supplement and productivity enhancer providing a safer and more consumer acceptable alternative to synthetic compounds in the late fattening period of Hanwoo steers. However, further study may be needed to better understand the present results in which herb feeding affected ruminal fermentation and produced various changes in carcass characteristics and blood metabolites in Hanwoo steers.

\section{ACKNOWLEDGEMENTS}

This work was carried out with the support of the "Cooperative Research Program for Agriculture Science and Technology Development (Project No. PJ004256)" Rural Development Administration, Republic of Korea

\section{REFERENCES}

AOAC. 1990. Official methods of analysis. 15th Ed. Association of official analytical chemists. Washington, DC.

Cardozo, P. W., S. Calsamiglia, A. Ferret, and C. Kamel. 2006. Effects of alfalfa extract, anise, capsicum, and a mixture of cinnamaldehyde and eugenol on ruminal fermentation and protein degradation in beef heifers fed a high-concentrate diet. J. Anim. Sci. 84:2801-2808.

Chattopadhyay, I., K. Biswas, U. Bandyopadhyay, and R. K. Banerjee. 2004. Turmeric and curcumin: Biological actions 
and medicinal applications. Curr. Sci. 87:44-53.

Chon, S. K. and N. S. Kim. 2005. Evaluation of silymarin in the treatment on asymptomatic Giardia infections in dogs. Parasitol. Res. 97:445-451.

Cropley, M., Z. Cave, J. Ellis, and R. W. Middleton. 2002. Effect of kava and valerian on human physiological and psychological responses to mental stress assessed under laboratory conditions. Phytother. Res. 16:23-27.

Davidson, P. M. and A. S. Naidu. 2000. Phyto-phenols. In: Natural Food Antimicrobial Systems (Ed. A. S. Naidu). CRC Press, Boca Raton, FL, USA, pp. 265-293.

Davidson, S., B. A. Hopkins, D. E. Diaz, S. M. Bolt, C. Brownie, V. Fellner, and L. W. Whitlow. 2003. Effects of amounts and degradability of dietary protein on lactation, nitrogen utilization, and excretion in early lactation Holstein cows. J. Dairy Sci. 86:1681-1689.

Dehghan, A., A. R. Ghasrodashti, A. Esfandiari, M. Mohebbi-Fani, M. B. Hoshyar, and K. Nayeri. 2011. Hepatoprotective effect of silymarin during negative energy balance in sheep. Comp. Clin. Pathol. 20: 233-238.

Dorman, H. J. D. and S. G. Deans. 2000. Antimicrobial agents from plants: antibacterial activity of plant volatile oils. J. Appl. Microbiol. 88:308-316.

Fenwick, F. R., J. Lutomski, and C. Nieman. 1990. Liquorice, glycyrrhiza glabra L-composition, uses and analysis. Food Chem. 38:119-143.

Galbraith, H., D. G. Dempster, and T. B. Miller. 1978. A note on the effect of castration on the growth performance and concentrations of some blood metabolites and hormones in British Fresian male cattle. Anim. Prod. 26:339-342.

Gazák, R., D. Walterová, and V. Kren. 2007. Silybin and silymarin: new and emerging applications in medicine. Curr. Med. Chem. 14:315-338.

Gettys, T. W., D. M. Henricks, and B. D. Schanbacher. 1988. An assessment of the relationship between tissue growth patterns and selected hormone profiles among sex phenotypes in cattle. Anim. Prod. 47:335-343.

Harmon, D. L., R. A. Britton, R. L. Prior, and R. A. Stock. 1985. Net portal absorption of lactate and volatile fatty acids in steers experiencing glucose-induced acidosis or fed a $70 \%$ concentrate diet ad libitum. J. Anim. Sci. 60:560-569.

Hosoda, K., K. Kuramoto, B. Eruden, T. Nishida, and S. Shioya. 2006. The effects of three herbs as feed supplements on blood metabolites, hormones, antioxidant activity, IgG concentration, and ruminal fermentation in Holstein steers. Asian-Aust. J. Anim. Sci. 19:35-41.

Hristov, A. N., T. A. McAllister, F. H. Van Herk, K. J. Cheng, C. J. Newbold, and P. R. Cheeke. 1999. Effect of Yucca schidigera on ruminal fermentation and nutrient digestion in heifers. J. Anim. Sci. 77:2554-2563.

Istasse, L., C. Vaneenaeme, A. Gabriel, A. Clinquart, G. Maghuinrogister, and J. M. Bienfait. 1990. The relationship between carcass characteristics, plasma hormones and metabolites in young fattening bulls. Vet. Res. Commun. 14: 19-26.

Kaneko, J. J., J. W. Harvey, and M. L. Bruss. 2008. Clinical biochemistry of domestic animals, 6th edn. Elsevier Academic, Amsterdam, pp. 356-365.
Kim, D. H., K. H. Kim, C. W. Choi, S. K. Hong, Y. J. Seol, E. G. Kwon, W. Y. Kim, I. S. Nam, S. S. Lee, and Y. K. Oh. 2009. Effects of thymol, eugenol and malate on in vitro rumen microbial fermentation. Korean J. Anim. Sci. Technol. 51:511520.

Kim, E. H., H. K. Kim, and Y. J. Ahn. 2003. Acaricidal activity of clove bud oil compounds against Dermatophagoides farinae and Dermatophagoides pteronyssinus (Acari: Pyroglyphidae). J. Agric. Food Chem. 51:885-889.

Lohakare, J. D., A. K. Pattanaik, and S. A. Khan. 2006. Effect of dietary protein levels on the performance, nutrient balances, metabolic profile and thyroid hormones of crossbred calves. Asian-Aust. J. Anim. Sci. 19:1588-1596.

Matsuoka, T., M. N. Novilla, T. D. Thomson, and A. L. Donoho. 1996. Review of monensin toxicosis in horses. J. Equine Vet. Sci. 16:8-15.

Mayer, K. E., R. P. Myers, and S. S. Lee. 2005. Silymarin treatment of viral hepatitis: a systematic review. J. Viral Hepat. 12:559-567.

Nagaraja, T. G. and M. M. Chengappa. 1998. Liver abscesses in feedlot cattle (A review). J. Anim. Sci. 76:287-298.

Nakajima, N., T. Utsunomiya, M. Kobayashi, D. N. Herndon, R. B. Pollard, and F. Suzuki. 1996. In vitro induction of anti-type $2 \mathrm{~T}$ cells by glycyrrhizin. Burns 22:612-617.

Nocek, J. E. 1997. Bovine acidosis: Implications on laminitis. J. Dairy. Sci. 80:1005-1028.

Pompei, R., O. Flore, M. A. Marccialis, A. Pani, and B. Loddo. 1979. Glycyrrhizic acid inhibits virus growth and inactivates virus particles. Nature 281:689-690.

Ramsey, J. J., M. E. Harper, and R. Weindruch. 2000. Restriction of energy intake, energy expenditure, and aging. Free Radic. Biol. Med. 29:946-968.

Rivera, J. D., S. E. Bachman, M. E. Hubbert, M. E. Branine, R. L. Horst, S. N. Williams, and M. L. Galyean. 2005. Serum and tissue concentrations of vitamin D metabolites in beef heifers after buccal dosing of 25-hydroxyvitamin D3. J. Dairy Sci. 88: 1364-1369.

Shin, K. J., Y. G. Oh, S. S. Lee, K. H. Kim, C. H. Kim, and B. H. Park. 2002. Feed intake evaluation of korean cattle (Hanwoo) fed diets containing different levels of compound feed in the growing and fattening periods. Korean J. Anim. Sci. Technol. 44:95-104.

Steinhour, W. D. and D. E. Bauman. 1988. Propionate metabolism: A new interpretation. p. 238-256 in Aspects of digestive physiology in ruminants (Ed. A. Dobson and M. J. Dobson). Comstock Publ. Assoc., Ithaca, NY.

Tedesco, D., A. Tava, S. Galletti, M. Tameni, G. Varisco, A. Costa, and S. Steidler. 2004. Effects of silymarin, a natural hepatoprotector, in periparturient dairy cows. J. Dairy Sci. 87: 2239-2247.

Temisan, V. 1989. Bulls, steers or heifers - which should be fattened in future? Tierzuchter 41:286-289.

Van Soest, P. J., J. D. Robertson, and B. A. Lewis. 1991. Methods for dietary fiber, Neutral detergent fiber, and nonstarch polysaccharides in relation to animal nutrition. J. Dairy Sci. 74:3583-3597.

Yun, Y. S., Y. Nakajima, E. Iseda, and A. Kunugi. 2003. Determination of antioxidant activity of herbs by ESR. J. Food Hyg. Soc. Japan 44:59-62. 